\title{
Can Physically Restrained Nursing-Home Residents Be Untied Safely? Intervention and Evaluation Design
}

\author{
Richard R. Neufeld, MD, Leslie S. Libow, MD, ${ }^{* \dagger}$ William Foley, PhD, ${ }^{S}$ and Harry White, MD*
}

OBJECTIVE: To develop an intervention that will enable nursing home personnel to remove physical restraints from nursing-home residents safely and cost effectively.

DESIGN: A multicenter prospective pre-post study.

SETTING: Sixteen high-restraint-use nursing homes, four each from California, Michigan, New York, and North Carolina. The 16 facilities has 2075 beds.

INTERVENTION: A 2-year educational demonstration study, including a 2-day workshop, specially prepared written and video materials, and telephone and on-site clinical consultations. Each nursing home designated a nurse to be the clinical coordinator and to lead a multidisciplinary team in conducting a restraint assessment and devising interventions for removal.

OUTCOME MEASURES: We compared pre- and post-study aggregate and individual facility rates of restraint use, incidents and accidents, family attitudes, financial impact, serious injuries, and staff attitudes and work patterns.

CONCLUSION: Preliminary data suggest that this intervention was well received and appears to be effective in achieving restraint-free care. J Am Geriatr Soc 43:1264-1268, 1995.

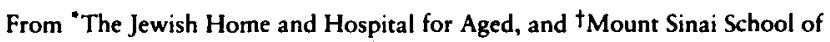
Medicine, New York, New York; Institute of Michigan, Wayne State University, Detroit, Michigan; and SRensselaer Polytechnic Institute, Troy, New York. Supported by a grant from The Commonwealth Fund

Address correspondence to Richard R. Neufeld, MD, Medical Director, The Jewish Home and Hospital for Aged, 120 West 106th Street, New York, NY 10025.
Tn the late 1980 s, approximately $40 \%$ of nursing-home Iresidents were physically restrained. ${ }^{1}$ Articles by Evans and Strump $\mathrm{f}^{2,3}$ and by Williams ${ }^{4,5}$ alerted health-care professionals to the fact that restraining nursing home residents, although a common practice throughout the nation, is unnecessary and often harmful. Tinetti et al. reported that restrained residents in nursing homes were more disoriented and more dependent in dressing than were nonrestrained residents. ${ }^{6} \mathrm{~A}$ team at Harvard found that nursing home residents who were restrained within 6 months of admission were also likely to become disoriented, dependent in dressing, incontinent of bladder and bowel, to behave inappropriately, to develop pressure sores, and to develop impaired mobility. Studies by hospital investigators documented a relationship between restraints and disruptive behavior and an increased risk of pressure sores and hospitalized acquired infections, as well as increased rates of in-hospital death. ${ }^{8-12}$

Prevention of falls and fall-related injuries are the major reasons for use of restraints. Restraints are commonly used for patients who fall despite the fact that only a small percentage of falls in nursing home residents result in significant injury. ${ }^{13,14}$ In addition, there is no evidence that restraints reduce falls or injury risk. A study in nursing homes by Tinetti et al. demonstrated that falls and injuries increased in frequency as restraint use increased. ${ }^{15}$ Falls may increase as restraints are carefully removed, but several studies have reported no increase in incidence of serious injuries. ${ }^{16-18}$

Dysfunctional and agitated behavior are often cited as reasons for applying restraints. Yet recent reports in the geriatric literature have implicated restraints in exacerbating agitated behavior, ${ }^{19}$ impairing social function ${ }^{20}$ and contributing to cognitive decline. ${ }^{21}$ Investigators in Minneapolis estimated that 200 residents each year may die as a result of restraints. ${ }^{22}$ Data in the psychological literature suggest a strong relationship between health and an individual's sense of control. Interventions that lead to a greater opportunity for control of daily activities appear to have a positive impact on the health of nursing home residents. ${ }^{23}$

The Omnibus Budget Reconciliation Act of 1987 (OBRA) included a legislative attempt to initiate a major restraint reduction movement and to define appropriate restraint use. According to OBRA, residents had the right to be free from physical or chemical restraints unless they were necessary to treat medical symptoms. ${ }^{24}$ This legislation went into effect despite mostly anecdotal reports and few, if any, multicentered systematic studies in nursing homes that documented "a dramatic reduction in untoward events from 
discontinuing restraints or an increase when they are imposed." 25

The purpose of this paper is to describe a clinical intervention program funded by the Commonwealth Fund and designed to reduce the use of physical restraints in nursing homes. We describe the intervention and define the outcomes we are measuring. Preliminary data have been encouraging and suggest a substantial reduction in restraint use with little change in serious injuries or the costs of care. Future papers will present the outcomes of this intervention program in detail.

\section{PROGRAM OVERVIEW}

In the summer of 1991, The Commonwealth Fund awarded The Jewish Home and Hospital for Aged (JHHA), the teaching nursing home affiliated with Mount Sinai School of Medicine, and Rensselaer Polytechnic Institute (RPI), a grant to develop a demonstration project to deal directly with the issue of excessive use of restraints, "Can Physically Restrained Nursing Home Residents Be Untied Safely?" Investigators from JHHA led the clinical intervention program that sought to devise and evaluate a clinical approach to restraint removal. The RPI team had responsibility for measuring the institutional consequences of restraint reduction.

Our goal was to educate and motivate the staff of 16 nursing homes with high rates of restraint use in creative individualized approaches to restraint-free care. We hypothesized that an "allowable" rate of restraint use within a 2-year period would be $5 \%$ or less, although the ultimate goal was total restraint-free care. We used OBRA's 1991 definition of physical restraints: that is, “any manual method or physical or mechanical device, material, or equipment attached or adjacent to the resident's body that the individual cannot remove easily which restricts freedom of movement or normal access to one's body" (interpretive guideline 483.13). ${ }^{26}$ At the onset of our project, side-rails were considered "accident hazards" and were not included in our study or analyses.

\section{METHODS}

We called our intervention "Retrain, Don't Restrain". The philosophy underlying the intervention was to empower nursing home staff to find alternatives to restraints by providing a broad outline of approaches for specific problem types. The intervention consisted of five components.

\section{Intervention}

\section{Educational Package}

This is directed to all levels of staff, family members, and residents. The package, now available for national distribution through the Washington, DC office of The American Association of Homes and Services for the Aging and The American Health Care Association, consisted of:

1. I Think We're Going to Make It, a 39-minute video

2. Reference Curriculum, an overview of the program for administrative staff that addressed issues of administrative concern such as legal liability, nursing home policies and procedures, and environmental modifications.

3. Clinical Coordinator's Guide, a how-to manual for the nurse in charge of setting up the program. The contents emphasizes the importance of staff morale and attitudes and family involvement. There are sections on strategies for enhancing participation of nursing assistants and for the ongoing process of resident assessment and restraint elimination.

4. Nursing Staff Workbook, a workbook directed to nursing staff with clinical cases and appropriate interventions. The cases are designed to serve as stimulus for problem solving and focus on the clinical assessment of residents with falling, behavior, positioning and wandering problems.

\section{Two-day Intensive Course}

Each facility sent two staff members to attend a 2-day intensive course to introduce the educational package, to provide hands-on experience and, at their facility, to instill a "can do" attitude. These two staff members were to implement a restraint free program at their facility with the help of onsite consultants

\section{Quarterly Site Visits}

Consultants from JHHA made onsite visits and were asked to educate and meet with resistant staff and family members and to attend team meetings when challenging cases were presented. The consultants often evaluated confused patients with histories of unsteady gaits and falls. These residents required weekly incremental interventions and referral for rehabilitation. Behavorially complex residents on psychotropic medications were also seen by the consultants, and these patients benefitted from behavior mapping over a 72-hour period, which alerted staff to patterns and routines.

\section{Telephone Consultation}

These consultations were more frequent early in the program and focused on program implementation and motivation of staff. It provided the JHHA consultation team a means of monitoring the progress and problems at each facility.

\section{Newsletter}

A newsletter was created to share successful strategies.

\section{Implementation}

Each participating nursing home designated a clinical nurse coordinator to assume responsibility for implementation. These responsibilities included organizing and leading the multidisciplinary restraint team, educating staff, functioning as an on-site resource, and communicating with the facilities' administrative staff.

Our educational package outlines the process and content for each nursing home's restraint-free initiative. We recommended that after the education of all staff is complete, the facility move through the units sequentially rather than attempting to effect change in an entire facility at once.

The clinical team, based at JHHA consisted of a geriatrician, a physiatrist, a nurse clinician and an occupational therapist. In pairs, the team made quarterly visits to provide consultation. These visits continued for 2 years or until a facility had a restraint rate of less than $5 \%$.

Nursing personnel frequently had an intuitive sense of which cases would be easy (no anticipated problems for restraint removal) or difficult ("challenge" cases). Challenge cases often required multiple interventions and repeated assessments. To avoid the inevitable frustration of being confronted late in the process with only the most difficult cases, we suggested challenge cases be evaluated once the team became confident. 
Although our goal was to eliminate restraints completely, we recognized that a few residents in each institution would benefit from temporary restraints until appropriate alternatives were found or until they became clinically stable. In all cases, the least restrictive restraint was sought.

\section{STUDY POPULATION AND INCLUSION CRITERIA}

We solicited interest from nursing homes in the top quartile of restraint use in four states (California, Michigan, New York, and North Carolina) where restraint rates were greater than $30 \%$. These states provided geographical representation, diversity in Medicaid reimbursement (case-mix versus flat rate), and a large number of potential participating nursing homes. Four nursing homes with restraint rates above the national median were selected randomly in each state, two large facilities with more than 100 beds and two smaller ones with fewer that 100 beds.

We chose nursing homes with high rates of restraint use in order to test our program under challenging but realistic conditions. In response to mailed informational packets, more than 150 nursing homes made preliminary commitments. Nursing homes for the demonstration project were drawn randomly from this group. Each nursing home in the project received a minimal financial incentive of $\$ 10 /$ per year per bed. Participants were reimbursed for all expenses incurred in attending the intensive workshop.

\section{OUTCOME MEASURES}

When a nursing home had maintained a restraint rate of less than $5 \%$ for two consecutive months, we designated it as a restraint-minimized facility and discontinued active clinical support. Six months after facilities were designated restraint minimized, or at the completion of the 2-year program, we are gathering data to measure the consequences of the program.

The evaluation design was a pre-post design that will measure changes in several dimensions of the nursing home. Outcomes are being examined both at the level of the individual resident (e.g., incidence of falls and significant injury, mobility status, frequency of agitation) and at the institutional level (e.g., staff attitudes, work sampling, financial impact). The clinical consultation team is collecting in-depth data on all 859 restrained residents and clinical information on those who sustained serious injuries during the 2-year demonstration project.

\section{EFFECT ON RESIDENTS}

Resident characteristics measured using the federally mandated Minimum Data Set for Resident Assessment and
Care Screening (MDS), ${ }^{27}$ were medical diagnoses, mental status, mobility and self-care skills, psychosocial well-being and behavior, continence, hearing and vision, medications, and activity patterns. The MDS is required at admission and then annually and whenever there are significant medical or functional status changes. Baseline MDS data are being compared with MDS data collected at the end of the demonstration period.

The onsite restraint team completed a "Restraint Review Worksheet" for every restrained resident. These worksheets are providing information about residents' functional problems, types of restraints, patterns of use, alternative interventions, and their outcomes.

\section{Incidents and Accidents}

We designed a form to record information on incidents and accidents. On the form, a member of the nursing staff described the accident, rated the seriousness of the injury on a scale of 1 through 5 , and suggested probably cause and prevention. All incident and accident data are being reviewed and collected for 3 months before and 3 months after the demonstration period. To maintain confidentiality, residents were not identifiable in either the MDS data base or incident and accident reports during the 3-month look-back periods.

\section{Effect on Staff}

We are examining whether restraint-free care results in changes in staffing levels, staff artitudes, and staff use of time. All administrative and caregiving staff answered a confidential attitude questionnaire (Appendix 1). A time-study anal$y$ sis is being performed before and after the program and will reveal how staff allocates their time and whether the time spent on specific tasks changed with the implementation of restraint-free care. ${ }^{28,29} \mathrm{We}$ are collecting data on eight categories of nursing activities (Table 1).

Direct care nursing staff on each unit and shift carried pocket beepers programmed to emit an audible signal at randomly determined times throughout the day. In response to the signal, staff members entered the activity being performed at that exact moment using a keypad on the beeper. Case-mix adjustment, will correct for any change in residents' diagnoses or severity of illness and control for changes in nursing care needs over time. ${ }^{30}$

\section{Family Acceptance}

We developed a survey to explore families' experiences with restraints, their feelings about the process of restraint reduction, and how much importance they attribute to restraint-free care, including its role in selecting a nursing

Table 1. Time Study Analysis of Nursing Activities

1. Activities of Daily Living (ADL)

2. Mobility

3. Floor duties

4. Social interactions

5. Direct monitoring

6. Nurse station activities

7. Medication and treatment

8. Personal time
Time spent with residents assisting or performing self-care tasks

(e.g., dressing, personal hygiene, toileting or feeding)

Assistance required by residents for change in location

Tasks such as housekeeping, providing linens, or answering phone

Visiting and speaking to residents, unrelated to direct personal care

Monitoring or supervising the actions of residents

Administrative and charting activities

Direct skilled nursing care other than ADL

Employee time for personal activities (meals, breaks) 
home. All families in demonstration nursing homes were mailed a questionnaire. To preserve confidentiality, the questionnaires were anonymous. Families are being surveyed 6 months after the project inception and again at the end of the project.

\section{Effect on Costs}

A model often used in analyzing costs and cost changes consists of measuring the overall cost change, adjusting this change for known effects, such as wage increases or inflation, and assigning the remainder to the variable under study. ${ }^{31,32}$ This is the model we used in this study.

Medicare and/or Medicaid cost reports pre and postdemonstration are being collected from participating nursing homes. Final step-down costs are being extracted and adjusted for capital costs, such as depreciation, loan interest, and cost categories not common for the 2 years under examination. We are calculating the difference in costs for individual facilities. To ascertain cost differences, adjustments are using the Medicare input price adjustment factor. Adjustments are being made for case-mix differences between the two time periods using a case-mix classification system such as RUG-III. This approach will categorize clinically meaningful conditions such as functional dependence or the need for special nursing care. ${ }^{30}$

Plant and equipment charges are being handled separately in the analysis of cost changes. We are collecting data that describes the equipment purchased or modifications (e.g., special chairs, alarm systems, orienting signs or altered exits) and the costs.

\section{CONCLUSION}

This demonstration model of restraint-free care focused on educating direct-care nursing home staff and supplementing the education with intensive clinical support. This model empowers nursing staff to assess residents and to develop individualized care plans without using restraints on residents who are at high risk for restraints.

The evaluation phase is tracking the decline in restraint use. It is also rigorously assessing the benefits and possible adverse consequences of dramatically reducing restraint use. A realistic perspective of the impact of restraint-free care will be achieved by systematically examining the safety and well being of nursing home residents, the concerns of family members, the effects on the employees and the financial implications for the institution. Papers on incidents, accidents and fracture rates, effective interventions, costs, family and staff attitudes, and patient and staff interactions and other outcomes will be forthcoming and should benefit all caregivers in their restraint reduction efforts.

\section{ACKNOWLEDGMENTS}

The authors are grateful for the insight and support of the Commonwealth Fund; to the Educational Development Corporation, a consulting group in Cambridge, Massachusetts, who helped design the workshop and educational materials; an to Dolores Newkirk for typing the manuscript, to Joan Dunbar for editing the manuscript, and to Camille Cohen.

\section{REFERENCES}

1. Health Care Financing Administration. Medicare/Medicaid Nursing Home Information. 1987-1988. Washington DC: US Government Printing Office, 1989.
2. Evans LK, Strumpf NE. Tying down the elderly: A review of the literature on physical restraint. J Am Geriatr Soc 1989;37:65-74.

3. Evans LK, Strumpf NE, Williams C. Redefining a standard of care for frail older people: Alternatives to routine physical restraint. In: Katz PR, Kane RL, Mezey MD, eds. Advances in Long-Term Care. New York: Springer, 1991, pp 81-108.

4. Williams CC. The experience of long-term care in the future. J Gerontol Soc Work 1989;14:3-18.

5. Williams $\mathrm{CC}$. Long-term care and the human spirit. Generations 1990; 14:25-28.

6. Tinetti M, Liu W, Marottoli R, Ginter S. Mechanical restraint use among residents of skilled nursing facilities: Prevalence, patterns, and predictors. JAMA 1991;265:468-471.

7. Stiebeling M, Schor J, Morris J, Lipsitz L. Morbidity of physical restraints among institutionalized elderly. J Am Geriatr Soc(Abstract) 1990:P108.

8. Frengley JD, Mion LC. Incidence of physical restraints on acute medical wards. J Am Geriatr Soc 1986;34:565-568.

9. Robbins LJ, Boyko E, Lane J et al. Binding the elderly: A prospective study of the use of mechanical restraints in an acure care hospital. J Am Geriatr Soc 1987;35:290-296.

10. Berland B, Wachtel TJ, Kiel DP et al. Patient characteristics associated with the use of mechanical restraints. J Gen Intern Med 1990;5:480-485.

11. Lofgren RP, MacPherson DS, Granier $R$ et al. Mechanical restraints on the medical wards: Are protective devices safe? Am J Public Health 1989;79:735-738.

12. Mion LC, Frengley JD, Jakovcic DA, Marino JA. A further exploration of the use of physical restraints in hospitalized residents. J Am Geriatr Soc 1989:37:949-956.

13. Rubenstein LZ, Robbins AS, Josephson KR et al. The value of assessing falls in an elderly population: A randomized clinical trial. Ann Intern Med 1990;113:308-316.

14. Neufeld RR, Tideiksaar R, Yew $E$ et al. A multidisciplinary falls consultation service in a nursing home. Gerontologist 1991;31:120-123.

15. Tinetti $M$, Liu W, Ginter $S$. Mechanical restraint use and fall related injuries among residents of skilled nursing facilities. Ann Intern Med 1992;116: 369-374.

16. Powell C, Mitchell-Pederson L, Fingerote E, Edmund L. Freedom from restraint: Consequences of reducing physical restraints in the management of the elderly. Can Med Assoc J 1989;141:561-564.

17. Ejaz $F$, Jones J, Rose M. Falls among nursing-home residents: An examination of incident reports before and after restraint reduction programs. J Am Geriatr Soc 1994;42:960-964.

18. Myer R, Kraenzle D, Gettman B, Morley J. The effect of reduction in restraint use in falls and injuries in two nursing homes. J Am Med Dir Assoc 1994;2:23-26.

19. Werner $P$, Cohen-Mansfield J, Braun J, Marx MS. Physical restraints and agitation in nursing-home residents. J Am Geriatr Soc 1989;37:1122-1126.

20. Folmar $\mathrm{S}$, Wilson $\mathrm{H}$. Social behavior and physical restraints. Gerontologist 1989;39:650-653.

21. Burton LC, German PS, Rovner BW, Brant LJ. Physical restraint use and cognitive decline among nursing home residents. J Am Geriatr Soc 1992;40:811-816

22. Miles SH, Irvine P. Deaths caused by physical restraints. Gerontologist 1992;32:762-766.

23. Rodin J. Aging and health: Effects of the sense of control. Science 1986;233:1271-1276.

24. Omnibus Budget Reconciliation Act. Federal Register V (54(21), Rules and Regulations. February 2, 1989.

25. Kane RL, Williams CC, Williams TF, Kane RA. Restraining restraints: changes in a standard of care. Ann Rev Public Health 1993;14:545-584.

26. Health Care Financing Administration. State operations manual. Transmittal 232. Baltimore: US Dept of Health and Human Services, September 1989.

27. Morris JN, Hawes C, Fries BE et al. Designing the national resident assessment instrument for nursing homes. Gerontologist 1990;30:293-207.

28. Niebel B. Motion and Time Study,. 8th Ed. Homeward, IL: Irwin, 1988.

29. Barnes RM. Motion and Time Study: Design and Measurement of Work, 7th Ed. New York: Wiley, 1980.

30. Fries BE, Schneider DP, Foley WJ et al. Refining a case mix measure for nursing homes: Resource Utilization Groups (RUG-III). Med Care 1994:32:668-685.

31. Kish L. Statistical Design for Research. New York: Wiley, 1987.

32. Johnson JB, Joslyn RA, Richard A. Political Science Research Methods, 2nd Ed. Washington, DC: Congressional Quarterly Inc, 1991. 
APPENDIX 1

NATIONAL NURSING HOME

RESTRAINT-FREE/MINIMIZATION PROJECT

\section{STAFF QUESTIONNAIRE}

Since Fall 1991, the nursing home you are working in has been part of a national project to eliminate restraint use in nursing homes. The project has resulted in a dramatic change in restraint usage. The project is soon corning to a close and information about how you now feel about restraint use is needed to judge the effectiveness of the program. If you were employed at this nursing home in the Fall of 1991 , you may recall that a similar questionnaire was given at the start of the program. By measuring your opinions now, we will be able to see how attitudes have changed as a result of the program to eliminate restraint use.

This questionnaire solicits your anonymous opinion on matters related to the care of nursing home residents. DONOT put your name on the questionnaire. Results of this survey will be reported in the aggregate only. Since one questionnaire cannot account for all of the possible opinions or all of the issues that are important to you and your residents, please mark the one answer that most closely matches your opinion by cireling or checking off the most appropriate response. There are 3 pages of questions in this booklet. Please answer all of the questions on all 3 pages.

The following definition of physical restraints is to be used when answering questions DEFINITION

Physical restraints are any physical or mechanical device or equipment attached to the resident's body that the individual cannot remove easily and that restricts freedom of movement. Mittens, waist restraints used in chairs, crisscross belts, and straps to tie down hands are examples of physical restraints. Bedrails are not considered to be physical restraints.

Please answer all questions as they apply to the nursing home in which you are currently employed.

\section{Rensselaer Polytechnic Institute, 1993}

\begin{tabular}{|c|c|c|c|c|}
\hline & {$\left[\begin{array}{c}\text { Sirongly } \\
\text { Agrec }\end{array}\right.$} & Agree & Oisagice & $\begin{array}{l}\text { Strongly } \\
\text { Disagree }\end{array}$ \\
\hline $\begin{array}{l}\text { 14. I primarily see my job as encouraging residents to do as much as } \\
\text { possible for themselves. }\end{array}$ & $\mathbf{I}$ & $\mathbf{2}$ & 3 & 4 \\
\hline $\begin{array}{l}\text { 15. Keeping restraint use very low: } \\
\text { a. Makes me feel better about my job. }\end{array}$ & 1 & 2 & 3 & 4 \\
\hline $\begin{array}{l}\text { b. Requires more alarm devices (e.g. bed alarms) and } \\
\text { adaptive devices (e.g. customized chairs) than are here now. }\end{array}$ & I & 2 & 3 & 4 \\
\hline c. Means that residents need more supervision. & $\mathbf{1}$ & 2 & 3 & 4 \\
\hline d. Means that more activities for residents are needed. & 1 & 2 & 3 & 4 \\
\hline $\begin{array}{l}\text { e. Promotes effective communication between staff and } \\
\text { residents. }\end{array}$ & I & $\overline{\mathbf{2}}$ & 3 & 4 \\
\hline $\begin{array}{l}\text { 16. A resident who is taking psychotropic medication is more likely } \\
\text { to be restrained. }\end{array}$ & $\mathbf{i}$ & 2 & 3 & 4 \\
\hline 17. Under no circumstances should residents be physically restrained. & 1 & 2 & $\overline{3}$ & 4 \\
\hline $\begin{array}{l}\text { 18. Residents develop more debilitating conditions (eg. contractures, } \\
\text { incontinence) when restrained. }\end{array}$ & 1 & 2 & 3 & 4 \\
\hline $\begin{array}{l}\text { 19. I would recommend the use of restraints for a resident who: } \\
\text { a. is confused. }\end{array}$ & i & 2 & 3 & 4 \\
\hline b. physically hurts herself, himself, or others. & $\mathbf{1}$ & 2 & 3 & 4 \\
\hline c. pulls out an IV or NG tube & $\mathbf{1}$ & $\mathbf{2}$ & 3 & 4 \\
\hline d. is left unattended in the bathroom. & 1 & 2 & 3 & 4 \\
\hline e. gets out of bed by herself. & $\mathbf{I}$ & 2 & 3 & 4 \\
\hline f. slides out of her chair. & $\mathbf{I}$ & 2 & $\mathbf{3}$ & 4 \\
\hline g. falls frequently. & $\mathbf{i}$ & $\mathbf{2}$ & 3 & 4 \\
\hline h. needs help with posture. & 1 & 2 & $\mathbf{3}$ & 4 \\
\hline i. When there are too few staff. & 1 & 2 & $\overline{3}$ & 4 \\
\hline $\begin{array}{l}\text { 20. The gosis of the restraint minimization program have been } \\
\text { communicated effectively to me. }\end{array}$ & 1 & $\mathbf{2}$ & $\overline{3}$ & 4 \\
\hline $\begin{array}{l}\text { 21. The opportunity exists for me to voice any dissatisfaction with the } \\
\text { restraint minimization program. }\end{array}$ & $\mathbf{1}$ & 2 & 3 & 4 \\
\hline 22. I feel that I have the opportunity to participate in decision-making & 1 & 2 & $\mathbf{3}$ & 4 \\
\hline $\begin{array}{l}\text { 23. I'm satisfied with the training in restraint minimization that I have } \\
\text { received. }\end{array}$ & $\mathbf{1}$ & $\overline{2}$ & $\overline{3}$ & 4 \\
\hline 24. My opinion is valued by my supervisor. & $\mathbf{1}$ & 2 & $\overline{3}$ & 4 \\
\hline $\begin{array}{l}\text { 25. I feel that I am kept up-to-date on issues affecting me and the } \\
\text { residents that I care for. }\end{array}$ & T & 2 & $\overline{3}$ & 4 \\
\hline
\end{tabular}

Please indicate the degree to which you agree or disagree with the following statements.

\begin{tabular}{|c|c|c|c|c|}
\hline & $\begin{array}{c}\text { Strongly } \\
\text { Agret }\end{array}$ & Agrec & Disagree & \begin{tabular}{|l|} 
Strongly \\
Disagree
\end{tabular} \\
\hline $\begin{array}{l}\text { 1. Because my facility uses few restraints, my work load is } \\
\text { greater than if I worked in a high restraint use facility. }\end{array}$ & 1 & 2 & $\overline{3}$ & 4 \\
\hline $\begin{array}{l}\text { 2. I am at greater risk for being legally liable for neglect if a } \\
\text { resident falls and is injured since I work at a low restraint } \\
\text { use facility. }\end{array}$ & 1 & 2 & 3 & 4 \\
\hline $\begin{array}{l}\text { The layout of my unit is suitable for restraint-free residents } \\
\text { to move around safely. }\end{array}$ & 1 & $\overline{2}$ & 3 & 4 \\
\hline $\begin{array}{l}\text { 4. Because this facility uses very few restraints: } \\
\text { a. More staff is needed. }\end{array}$ & 1 & 2 & 3 & 4 \\
\hline b. The safety of the residents has been jeopardized. & 1 & $\mathbf{2}$ & $\overline{3}$ & 4 \\
\hline c. Residents fall more frequently. & 1 & 2 & 3 & 4 \\
\hline d. Staff could be more easily harmed. & $\mathbf{T}$ & 2 & $\mathbf{3}$ & 4 \\
\hline e. Residents are more likely to wander. & $\mathbf{1}$ & $\mathbf{2}$ & 3 & 4 \\
\hline $\begin{array}{l}\text { f. Residents have been given more psychotropic } \\
\text { medication. }\end{array}$ & $\overline{1}$ & $\overline{2}$ & 3 & 4 \\
\hline $\begin{array}{l}\text { 5. Restraining a resident is an invasion of a basic right of all } \\
\text { human beings. }\end{array}$ & $\overline{1}$ & 2 & $\overline{3}$ & 4 \\
\hline 6. Keeping restraint use low is worth the risks involved. & 1 & $\overline{2}$ & 3 & 4 \\
\hline $\begin{array}{l}\text { 7. I feel I am very aware of the needs of the residents I work } \\
\text { with. }\end{array}$ & $\overline{1}$ & 2 & $\overline{3}$ & 4 \\
\hline $\begin{array}{l}\text { 8. I feel that the majority of restraints in use at this facility are } \\
\text { necessary. }\end{array}$ & 1 & 2 & 3 & 4 \\
\hline $\begin{array}{l}\text { 9. Residents who are not restrained are more likely to be } \\
\text { agitated. }\end{array}$ & $\overline{1}$ & 2 & $\overline{3}$ & 4 \\
\hline $\begin{array}{l}\text { 10. Using few restraints interferes with the medical treatment of } \\
\text { residents. }\end{array}$ & $\overline{1}$ & $\overline{2}$ & 3 & 4 \\
\hline $\begin{array}{l}\text { 11. When residents are restrained, they tend to: } \\
\text { a. Feel more secure (safer) }\end{array}$ & 1 & $\mathbf{2}$ & 3 & 4 \\
\hline b. Feel angry & $\mathbf{1}$ & 2 & $\mathbf{3}$ & 4 \\
\hline c. Feel fearful & 1 & 2 & 3 & 4 \\
\hline d. Become more dependent & 1 & 2 & 3 & 4 \\
\hline e. Feel humiliated & 1 & 2 & $\overline{3}$ & 4 \\
\hline f. Feel physical discomfort & $\overline{1}$ & $\overline{2}$ & $\mathbf{3}$ & 4 \\
\hline g. Feel helpless & $\mathbf{T}$ & $\mathbf{2}$ & $\mathbf{3}$ & 4 \\
\hline h. Feel trapped & $\mathbf{T}$ & $\mathbf{2}$ & $\mathbf{3}$ & 4 \\
\hline 12. I see my job as primarily taking care of and helping residents & $\mathbf{1}$ & 2 & $\mathbf{3}$ & 4 \\
\hline 13. Residents are calmer when restraint-free. & T & 2 & $\mathbf{3}$ & 4 \\
\hline
\end{tabular}

Check only one answer for each of the following
26. Your job title:

ORN

DLPN

$\checkmark$ Aide/Orderly

Nursing Supervisor

$\square$ Other (specify)

28. Highest level of education completed: Less than high school

Graduated from high school

Q Some college

$\square$ Two year college

a Four year college

Graduate (Master's or above)

$\square$ Other (specify)

30. I was working here before Nov., 1, 199 ] QYES O NO
27. Your usual shift:

7:30 a.m. - 3:30 p.m.

Q 3:30 p.m. - 11:30 p.m.

Q 11:30 p.m. - 7:30 a.m

0 Other (specify)

29. Do you think that this education was important for your job?

口YES $\square$ NO

Y Y

31. Time employed at this facility:

$\square$ Less than 6 months

6 months to less than 1 year

1 to less than 2 years

2 to less than 4 years

4 years or more
32. Age: Sex: a Female Q Male Ethnicity: 1 Hispanic
Q Caucasian, White $\square$ Assian
Oother

Comments/Suggestions: (write in)

Thank you for your cooperation! 